\title{
DNA barcoding and evolutionary lineage of banana skipper Erionota torus (Evans) (Lepidoptera: Hesperiidae) from Malabar, a part of Southern WesternGhats, India
}

\author{
K. Abdul Jaleel ${ }^{1 *}$, S.M. Ghosh ${ }^{2}$, V. Jiji Joseph ${ }^{3}$ \\ ${ }^{1}$ Department of Zoology, Government College, Vidhyanagar, Kasaragod, Kerala-671123, India \\ 2 Department of Molecular Biology, Kannur University, Nileswar, Kasaragod, Kerala-671314, India \\ ${ }^{3}$ Department of Zoology, Government Brennen College, Dharmadam, Thalassery, Kerala-670106, India \\ *Corresponding Author: jaleelkabdul@gmail.com, Tel.: +91-9995-417121
}

Available online at: www.isroset.org

Received: 25/Jul/2019, Accepted: 24/Aug/2019, Online: 31/Aug/2019

\begin{abstract}
All Severe incidence of banana leaf roller Erionota spp. has been noticed in banana plantations of Malabar region of Kerala a part of Western Ghat, India. It is currently proposed that banana defoliater E. thrax and E. torus occur together in Kerala and many researchers have treated them as a single species. At present there is no published information regarding whether, one or both the species of Erionota coexist during the occasional outbreak of banana skipper in Kerala. Also it is unknown whether in the field the associated parasitoids attack both species, equally or showed some preference for one or the other . This information is essential for the implementation of effective biological control programmes against this pest. Since the early stages of E. thrax and E. torus cannot be distinguished easily, and as they are common pests of banana, morphological identification of species is difficult. The present study is aimed to confirm the Erionota species from Malabar region of Kerala by using a molecular genetic approach. We sequenced the partial mitochondrial cytochrome oxidase I gene sequence (COI ) having 650 base pair DNA from specimens collected from selected localities of Malabar region of Kerala ,India. The COI sequences of the banana skipper supported the existence of E.torus species in the infested areas and all the parasitoid species collected during the course of study where that of E.torus .
\end{abstract}

Keywords - Erionota torus, Erionota thrax,COX I,DNA barcoding ,Musa spp.

\section{INTRODUCTION}

Banana(Musa sp.) is a crop of high importance to human societies, and account to the fourth most important food in the world today[1]. Banana serves as an ideal and low cost food source for developing countries where most of the population depend mostly on bananas as food. Its parts are used as insecticide, antioxidant,as colour absorber, in the preparation of various functional foods, wine, alcohol, biogas and also as cattle feed[2].

Kerala is one of the major banana producing states of India. Banana yields are continuously declining due to attack by insect pests. Insects attack the banana rhizome, pseudostem, leaf and fruit. The major pests include the banana weevil, pseudostem weevil, banana scab moths, banana skipper, banana thrips and banana aphids[3].During September October 2013, epidemic build up of leaf roller pest Erionota was noticed in banana plantations at several places in Kerala viz., Peechi, Palghat and Nilambur [4]. The survey held in southern districts of Kerala, South India revealed the presence of the banana leaf roller Erionota in all most all important banana varieties and infestation was up to $40 \%$ and severe defoliation of Musa spp. with mean leaves damaged per plant to 2.88. \% [5]..Erionota spps are the major defoliators of Musa spp. where they overlap in distribution in the mainland of South-East Asia and in the Southern Philippines where E. thrax and E. torus have not been distinguished in the economic literature[6]. Both Erionota thrax and Torus were reported from Kerala [7]..Erionota thrax and E.torus have similar morphology often making their distinction by classical physical criteria difficult[6].Separation of the two species, particularly the females, is only reliable if based on the examination of the genitalia [7]. Since there is no reliable way to separate the early stages of E. thrax, E. torus and E. acroleuca morphologically,a careful study and documentation of reared material, supported by reared vouchers and barcoding of individuals, is needed[6].DNA barcode based identification has been proposed as a molecular method for assigning individual specimens to known species [8].DNA barcode involves DNA sequence analysis of a portion of the 
mitochondrial gene cytochrome $c$ oxidase subunit I (COI)of about 600-700 bp. The basic concept is that barcode variation between even closely related species will be substantially greater than that observed within species. The "barcoding gap", with a 10-fold difference between mean interspecific and intraspecific variations being frequently mentioned as a minimum threshold for the specific assignment of unknown individuals to a species [8]. Also even the absence of such gaps may still allow accurate assignment of barcode sequences to species in at least some taxa[9].150 lepidopteran specimens were correctly identified using a barcode database of 200 closely allied species [7]. The barcoding technique was successfully applied in species identification approximately 3500 species of moths, butterflies, flies, and wasps [10].Barcode comparisons were able to discriminate between four closely related Helicoverpa species of family Noctuidae as Spodoptera[11]..Even though nearly $16 \%$ of described species are created worldwide, in India only $4.6 \%$ of barcode has been created out of 59,000 described insect pests [12]. The objective of this study was to assess the applicability of DNA barcoding to identify Erionota spp. which cause serious damage to banana in Malabar region of Kerala, India.

\section{RELATED WORK}

Referring to an un named image by clerck ,the taxonomy of Papilio thrax from Java was described by Linnaeus [13] Honey and Scoble [14]conclude that there are two specimens of E. thrax in the Linnean Collection, one of which has been designated the lectotype. Evans narrated E. torus from Sikkim and gave characters to separate the adults from E. thrax based on appearance and male genitalia and Kunte stated that the separation of the two species of E.thrax and E.torus, is only reliable if based on examination of the genitalia[13]. Bascombe et al. illustrates male genitalia and female venation of E. torus from Hong Kong[13].Molecular level identification by DNA barcoding is needed to confirm the early stages of the pest to plan effective management strategies .

\section{METHODOLOGY}

a. DNA preparation and PCR amplification of the COI region:The larvae of butterflies of Erionota spp were collected from banana plantations of Malabar region a part of Western Ghats in Kerala. After the emerged adult of the collected larva were preserved in the laboratory at ${ }^{-} 20^{\circ} \mathrm{C}$ before genomic DNA extraction..The genomic DNA of Erionota torus was isolated from one of the leg muscles, using 'kit Macherey-Nagel Nucleospin Tissue' (MacheryNagel, Duren, Germany) following the Manufacturer's protocol. PCR amplification was performed in the PCR reaction mixture consisted of 2 nanograms of genomic DNA in $1 \mu \mathrm{l}, 1 \mu \mathrm{l}$ each forward and reverse primers at a concentration of $10 \mu \mathrm{M}, 2.5 \mu \mathrm{l}$ of dNTPs $(2 \mathrm{mM}), 2.5 \mu 110 \mathrm{X}$ reaction buffer, $0.20 \mu \mathrm{lTaq}$ polymerase $(5 \mathrm{U} / \mu \mathrm{l})$ and $16.8 \mu \mathrm{l}$ $\mathrm{H}_{2} \mathrm{O}$. The thermo cycling program consisted of $95^{\circ} \mathrm{C} / 3$ minutes for initial denaturation followed by 45 cycles of $95^{\circ} \mathrm{C} / 10$ seconds, $50^{\circ} \mathrm{C} / 45$ seconds, $72^{\circ} \mathrm{C} / 45$ seconds and with a final extension of $72^{\circ} \mathrm{C}$ for 3 minutes. The PCR amplified product was column purified using Mo Bio Ultra Clean PCR Clean-up Kit (Mo Bio Laboratories, Inc. California) as per the Manufacturer's instructions.

b. DNA sequencing and analysis:The purified product was sequenced with forward and reverse primers using the Sanger's sequencing method at Sci Genome Labs, Cochin. The forward and reverse sequence was aligned and the consensus sequence was used for analysis. The phylogeny analysis was done using the NCBI nucleotide BLAST software (http://www.blast.ncbi.nlm.nih.gov/Blast.cgi). KT783538.1

\section{RESULTS AND DISCUSSION}

Banana skipper butterflies Erionota spp. have brown bodies with large heads, large red eyes and thickened, curved antennae tips. Each wing is $31-37 \mathrm{~mm}$ wide, with three yellow areas on the forewings. Forewing outer margin is rounded and larger in size. In the male apex is not white above and below. Hind wing is some what broader and the outer margin is more evenly rounded. They have stouter body with antenna having shaft which is conspicuously white below through out.(Fig 2.D)Adult butterflies lay small, pale yellow eggs on the under sides of banana leaves. Eggs are small, bright yellow, turning to orange, bright red and then to cream colored when mature. Eggs are laid singly or in clusters of about 10-25 on the lower surface of banana leaves. The eggs are laid at morning or evening, when the butterflies are most active.

The eggs measured $1.7 \pm 0.17 \mathrm{~mm}$, in diameter and $1.2 \pm 0.15$ in height, with the dark flat round area on top; there are $27 \pm 2$ fine ribs. They are usually pale yellowish which turns orange in color later. Eggs show considerable variation in color pattern(Fig 1A).The eggs hatch in about one week(Fig 1B). There are five larval instars. Immediately after hatching, the first instar larvae of 3-4mm length move towards the margin of the leaf and begin to feed (Fig 1C,1D) and starts to build shelters by rolling and pasting the edge of the leaf using a sticky substance secreted by the larva(Fig.3.A\&B). The larvae pupate and form the yellowish brown, long and cylindrical pupa(Fig.2C).The duration of pupa varies but an average of $10 \pm 1$ days are required to hatch.

Phylogeny analysis of Erionota torus when carried out by the partial sequencing of the mitochondrial COI yielded a 630 bp product by PCR amplification. GenBank deposition indicated the novel and first time records of Erionota torus 
in Malabar region of Kerala and was provided with accession numberKT783538.1. The phylogenetic tree was constructed by Fast Minimum Evolution method(Fig.4) and Neighbour joining(Fig5) . Genbank analysis showed the sequence E.torus has $98.10 \%$ similarity with that of E.thrax (GenBank accession number:KY019746.1) is its nearest neighbour.

The phylogenetic tree constructed by Neighbor joining method using the partial nucleotide sequence of COI gene also indicates that both Erionota thrax and Erionota torus are monophyletic species. The early stages of E. thrax and $E$. torus are similar and they are common pests of banana. Morphological identification of the early stages of two species is difficult. Since there is no published information regarding whether, one or both the species of Erionota coexist during the occasional outbreak of banana skipper in Malabar region of Kerala. The correct species level information will be highly useful in implementing effective control programmes against this invasive pest.
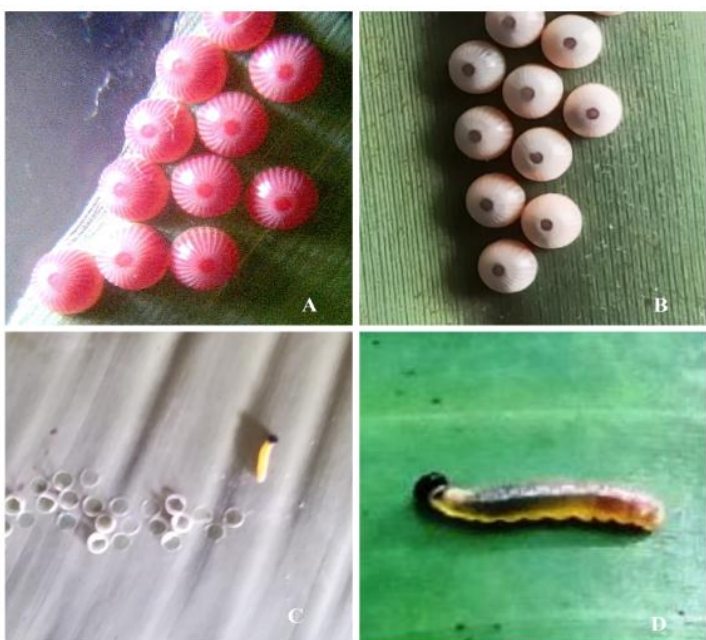

Fig.1. A.Egg , B.Egghatching, C\&D. Early instar larvae
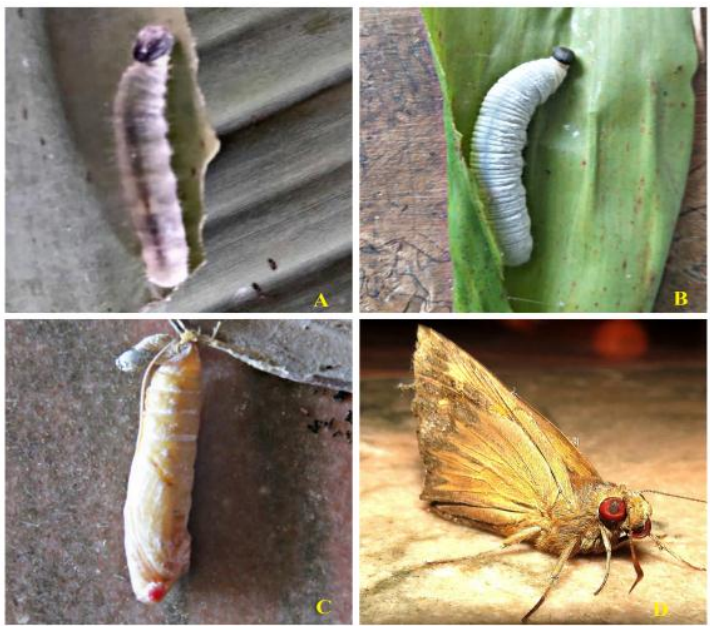

Fig.2 A\&B.Late instars ,C.Pupa,D.Adult,
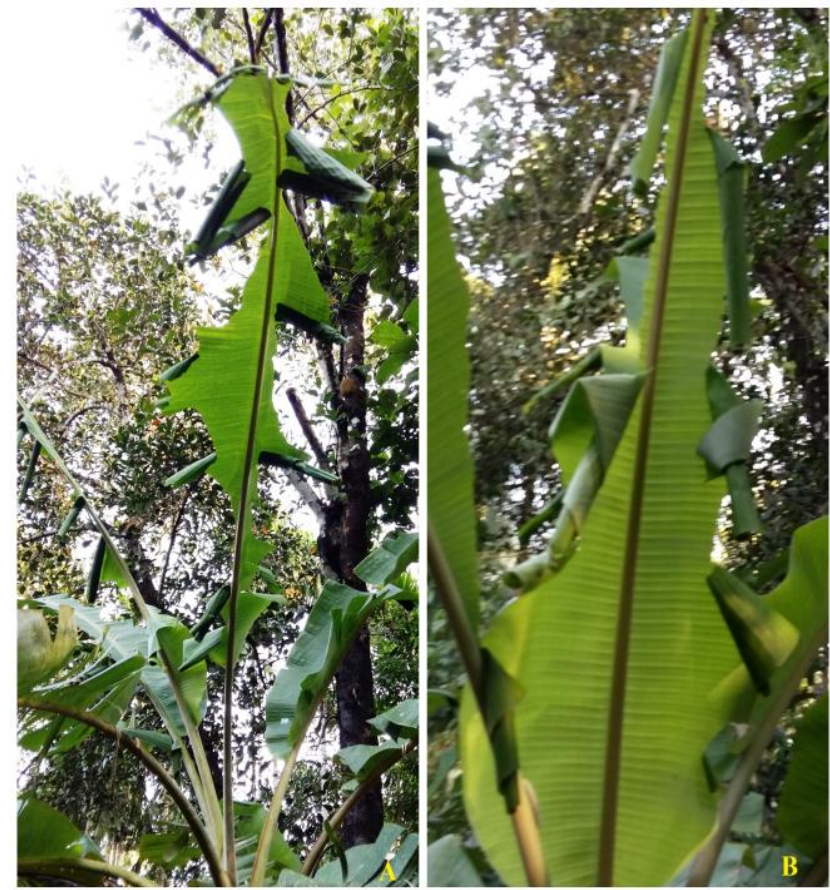

Fig.3. A.Infested banana plant and B.Banana leaf rolls.

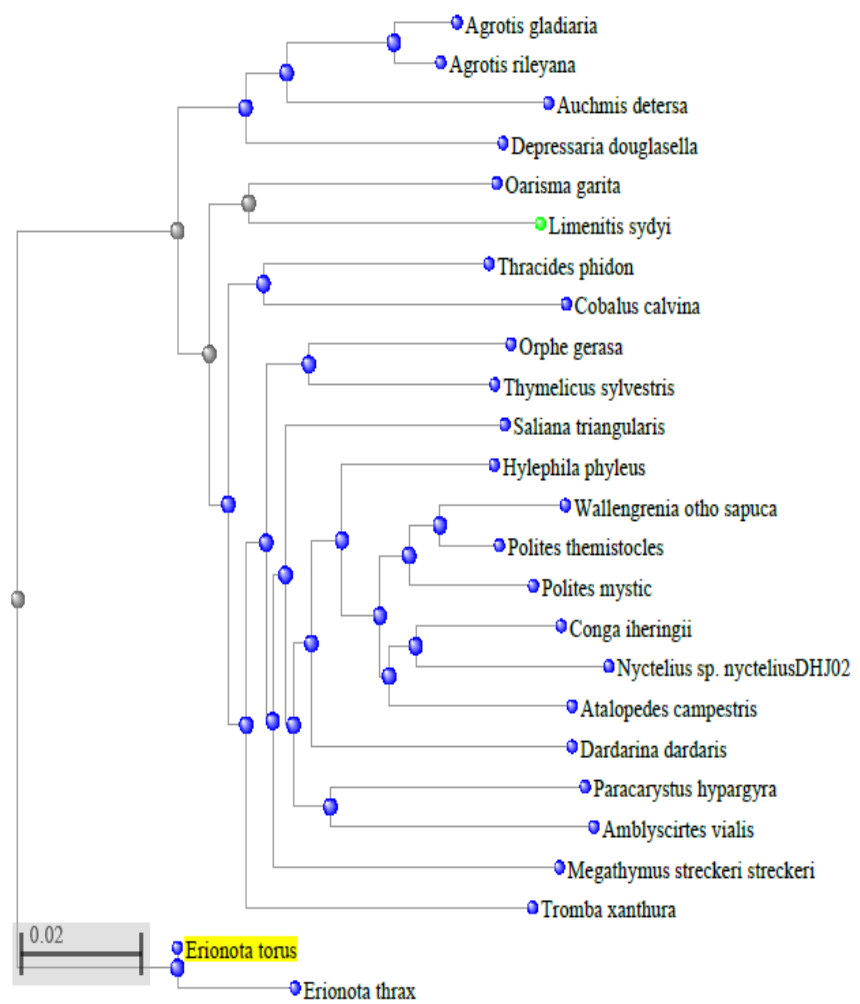

FIG.4. EVOLUTIONARY RELATIONSHIPS OF ERIONOTA TORUS. THE PHYLOGENETIC TREE WASCONSTRUCTED BY FAST MINIMUM EVOLUTION METHOD USING THE PARTIAL NUCLEOTIDE SEQUENCE OF COI GENE 


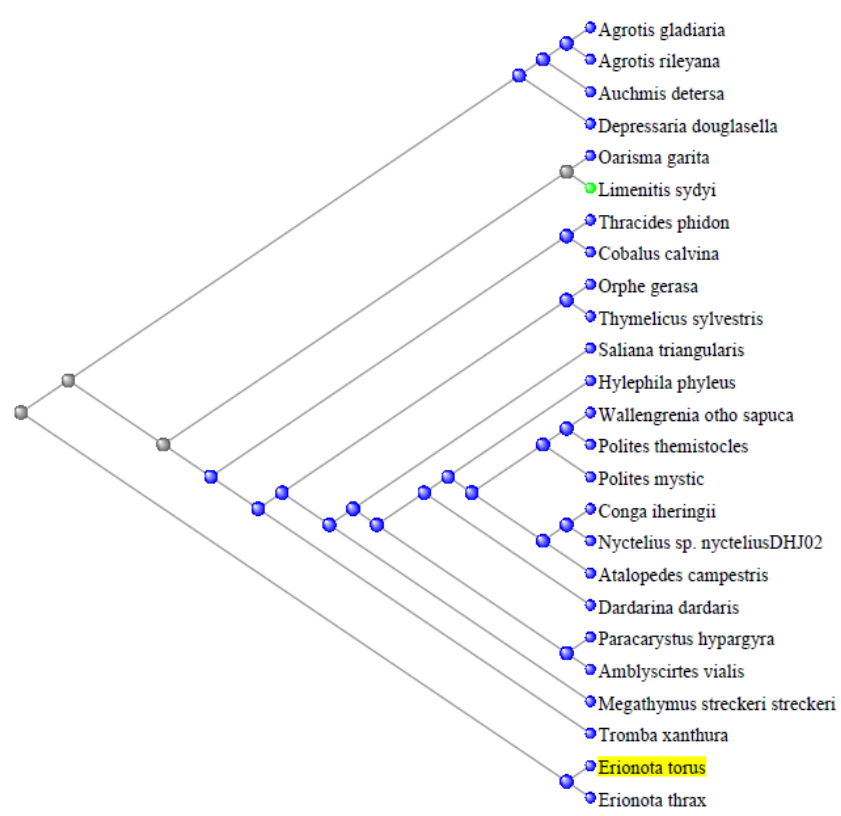

FIG.5. EVOLUTIONARY RELATIONSHIPS OF ERIONOTA TORUS. THE PHYLOGENETIC TREE WAS CONSTRUCTED BY NEIGHBOURJOIONING METHOD USING THE PARTIAL NUCLEOTIDE SEQUENCE OF COI GENE

\section{CONCLUSION}

By DNA barcoding and evolutionary lineage study first time it is concluded that the heavy infestation on banana plants during monsoon and post monsoon season in Malabar region of is due to Erionota torus. The sequenced the COI , 650 base pair DNA 'barcode' region of the mitochondrial gene cytochrome c oxidase I (COI) from specimens collected from selected localities indicates and confirms the existence of E.torus species in the infested areas of Malabar region of Kerala. It is concluded that DNA barcoding is a reliable technique for species level identification banana skipper.This will be helpful in the development of more effective pest management options for effective control of this pest.

\section{ACKNOWLEDGMENT}

The authors gratefully acknowledge the Department of Zoology Government college Kasaragod and Government Brennen College Thlalassery for the technical support.

\section{REFERENCES}

[1] S.C Nelson, C.Randy . Ploetz, and Angela Kay Kepler, "Banana and plantain - an overview with emphasison Pacific island cultivars",Species Profiles for Pacific Island Agroforestry.Vol. 2,Issue.2,pp.167-181, 2006.

[2] D Mohapatra, Sabyasachi Mishra and Namrata Sutar. "Banana and its by-product utilisation: an overview",Journal of Scientific \& Industrial Research,Vol. 69, pp. 323-329,2010
[3] W.Tinzaara, C.S.Gold . (2008) Banana Pests and Their Management. In: Capinera J.L. (eds) Encyclopedia of Entomology. Springer, Dordrecht pp.2,2008.

[4] K.C.Soumya , T.V.Sajeev, T.K.Maneetha, Keerthy Vijayan and George Mathew.Incidence of "Erionotathrax(Hübner) (Lepidoptera:Hesperiidae) as a pest of banana in Kerala". Entomon Vol. 38, Issue.1, pp.53-58, 2013.

[5] T. Sivakumar, T.Jiji and N.Anitha,, "Field observations on banana skipper ErionotathraxL. (Hesperiidae: Lepidoptera) and its avian predators from southern peninsular India", Current Biotica, Vol. 3, Issue.8, pp.220-227, 2014.

[6] M.J.Cock,(2015). "A critical review of the literature on the pest Erionota spp. (Lepidoptera, Hesperiidae): taxonomy, distribution, food plants, early stages, natural enemies and biological control". CAB Reviews, Vol. 10, Issue.7, pp.1-30, 2015.

[7] Raju, D., K. Kunte, S. Kalesh, V. K. Chandrashekaran, Manoj P, H. Ogale\& R. Sanap. 2018. "Erionota torus Evans, 1941 Rounded Palm-redeye”, Butterflies of India, Vol. 2, Issue.56, 2018.

[8] P.D.N. Hebert , A.Cywinska A, S.L.Ball , J.R.deWaard . "Biological identifications through DNA barcodes". Proceedings of the Royal Society of London B-Biological Sciences. Vol.270,Issue.1512,pp313-321,2003.

[9] Lou M, Golding GB. (2010) "Assigning sequences to species in the absence of large interspecific differences", Molecular Phylogenetics and Evolution,Volume 56, Issue 1:pp187-194,2010.

[10] S. D.H.Janzen , W.Hallwachs and P.Blandin P "Integration of DNA barcoding into an ongoing inventory of complex tropical biodiversity", Molecular Ecology Resources. Vol. 9, Issue.1, pp.126, 2009.

[11] G.T. Behere, D.Russell , P.Batterham and W.T. Tay , "Two species into one: Bottleneck history of Helicoverpazeafrom Helicoverpaarmigera revealed by DNA barcoding", Journal of Insect Science. Volume 7,Issue 1,2007.

[12] S.K.Jalali,R.Ojha and T.Venkatesan (2015) . "DNA barcoding for identification of agriculturally important insects.In New Horizons in Insect Science : Towards sustainable Pest management" .Springer India, pp.13-23, 2015.

[13] M.J.Cock,(2015). "A critical review of the literature on the pest Erionota spp. (Lepidoptera, Hesperiidae): taxonomy, distribution, food plants, early stages, natural enemies and biological control". CAB Reviews, Vol. 10, Issue.7, pp.4, 2015.

[14] R.Honey and J.Scooble"Linnaeus's butterflies (Lepidoptera: Papilionoidea and Hesperioidea)",Zoological Journal of the Linnean Society ,pp 386-387, (2001),. 